\title{
Atividades das enzimas peroxidase (POD) e polifenoloxidase (PPO) nas uvas das cultivares benitaka e rubi e em seus sucos e geléias
}

\author{
Effect of peroxidase (POD) and polyphenoloxidase enzymes (PPO) on Benitaka and Rubi \\ grape cultivars and on products processed in the form of juice and jelly
}

Andreia Andrade de FREITAS ${ }^{1}$, Maria Fernanda FRANCELIN ${ }^{1}$, Gláucia Freitas HIRATA ${ }^{1}$, Edmar CLEMENTE ${ }^{1 *}$, Flávio Luis SCHMIDT ${ }^{2}$

\section{Resumo}

A peroxidase e a polifenoloxidase estão relacionadas com o escurecimento de frutas, por isso o controle das atividades destas enzimas é de grande importância para a tecnologia de alimentos. Neste trabalho estudaram-se as atividades dessas enzimas nas uvas frescas das cultivares Benitaka e Rubi, bem como as suas termoestabilidades e as suas atividades enzimáticas residuais no suco e nas geléias (extra e light). Foi também avaliada a qualidade microbiológica dos produtos elaborados. As atividades da enzima POD, tanto da fração solúvel quanto da ionicamente ligada, foram semelhantes nas uvas das duas variedades, Benitaka e Rubi. A atividade da enzima polifenoloxidase foi maior na variedade Rubi. As operações de cocção e pasteurização foram mais eficientes para baixar as atividades enzimáticas residuais da POD e PPO quando aplicadas às geléias de uva, em comparação com o suco. Embora não foram suficientes para a total inativação enzimática, essas operações reduziram-nas consideravelmente, e foram eficientes para garantir seguridade microbiológica dos produtos, geléias e suco.

Palavras-chave: Vitis vinifera L; peroxidase; polifenoloxidase; termoestabilidade.

\begin{abstract}
Peroxidase (POD) and polyphenoloxidase (PPO) are oxidative enzymes related to the darkening process suffered by fruits. Thus, the control of the effects of these enzymes, in the preservation of fruit, in order to minimize the darkening process is considered of great importance for food processing technology. The present study investigated the effects of POD and PPO on fresh grapes from Benitaka and Rubi cultivars, as well as the thermal stability and the residual enzymatic activities in the processing of juice and jelly (extra and light). Moreover, the microbiological quality of the processed products was evaluated. It was observed that, the effect of the POD enzyme, from the soluble fraction, as well as from the ionically bound fraction, was similar in both varieties of grapes, Benitaka and Rubi. But the effect of the PPO enzyme was higher in the Rubi variety. Operations such as cooking and pasteurizing were the most efficient processes to reduce the residual enzymatic effect of POD and PPO in grape jelly, in comparison to the juice. Although such processes were not enough for total enzymatic inactivation, they permitted a considerable reduction, thus were efficient to guarantee the microbiological safety of the products, such as jelly and juice.

Keywords: Vitis vinifera L.; peroxidase; polyphenoloxidase; thermostability.
\end{abstract}

\section{Introdução}

A produção brasileira de uvas em 2002 foi de 1.148 mil toneladas, sendo que o Paraná respondeu por $8,6 \%$ do total (SATO et al., 2004). A produção paranaense abrange duas regiões distintas: nas proximidades de Curitiba são produzidas uvas americanas e híbridas destinadas à vinificação e ao mercado "in natura"; e no norte do Estado, a exploração é altamente tecnificada, propiciando duas safras anuais, sendo exploradas cultivares de uva fina de mesa, como a Itália e a Rubi (GIOVANNINI, 1999). A cadeia produtiva da uva fina é importante para o Brasil, pois sua contribuição nas exportações foi de cerca de 59,9 mil toneladas em 2003, gerando US\$37,6 milhões e perdendo em participação somente para a manga (SATO et al., 2004).

Devido à sua fragilidade, as uvas são muito perecíveis, sendo difícil evitar deteriorações destas frutas. As perdas pós- colheita têm sido estimadas em cerca de $27 \%$ da produção total, sendo estas principalmente de origem mecânica, fisiológica e de infecção microbiana (BARTHOLO, 1994).

A respeito das regras fisiológicas, de frutos e vegetais, já está estabelecido que sua deterioração, mudança no sabor, na textura e no valor nutricional são ocasionados também por enzimas do grupo das oxiredutases (LEE; PENNESI; DICKSON, 1984; SCIANCALEPORE; ALVITI, 1985; ROBINSON, 1987).

A peroxidase (POD) é do grupo das oxidoredutases, sendo capaz de catalisar um grande número de reações oxidativas em plantas usando peróxido como substrato, ou, em alguns casos, oxigênio como um aceptor de hidrogênio. Em vegetais, a peroxidase induz a mudanças negativas de sabor

Recebido para publicação em 16/11/2006

Aceito para publicação em 7/8/2007 (002058)

Departamento de Agronomia, Pós-graduação em Agronomia - PGA, Universidade Estadual de Maringá - UEM, Av. Colombo, 5790, CEP 87020-900, Maringá - PR, Brasil, E-mail:eclemente@uem.br

2 Departamento de Tecnologia de Alimentos - DTA, Faculdade de Engenharia de Alimentos - FEA, Universidade Estadual de Campinas - UNICAMP, CP 6121,

CEP 13083-970, Campinas - SP, Brasil, E-mail: schimidt@fea.unicamp.br

${ }^{*}$ A quem a correspondência deve ser enviada 
durante a estocagem. É considerada a enzima vegetal mais estável ao calor e sua inativação tem sido convencionalmente usada como indicador de adequação de branqueamento em processamentos vegetais.

As enzimas peroxidase e polifenoloxidase são responsáveis pelo escurecimento em frutas, vegetais e seus produtos processados, por isso o controle das atividades destas enzimas é de grande importância durante a transformação dessas matériasprimas para a obtenção de produtos processados (CLEMENTE; PASTORE, 1998).

Considerando a importância de aproveitar as uvas das cultivares Benitaka e Rubi, que não receberam classificação para o comércio in natura e tendo por meta agregar maior valor à produção, a pesquisa teve por proposta avaliar as atividades das enzimas peroxidase e polifenoloxidase dessas uvas, relacionando-as com a qualidade dos produtos delas processados, o suco e as geléias. Foram determinadas suas atividades enzimáticas em uvas frescas, a termoestabilidade destas enzimas, bem como suas atividades residuais nos produtos processados.

\section{Material e métodos}

As uvas (Vitis vinifera L.) das variedades Rubi e Benitaka consideradas fora do padrão para comercialização in natura foram fornecidas pela Cooperativa localizada na cidade de Marialva, Estado do Paraná, safra de dezembro de 2005. As uvas apresentaram características consideradas não atrativas ao consumidor, como baixo peso e má formação dos cachos, e por isso eram comercializadas por um baixo valor.

Uvas frescas das variedades Rubi e Benitaka, maduras e isentas da ação de patógenos foram selecionadas para as análises químicas e enzimáticas. Para o processamento da geléia light foram utilizadas uvas das variedades Rubi e Benitaka, além de pectina cítrica GENU ${ }^{\circledR}$ tipo 8002 de baixa metoxilação e CP KELCO, maltodextrina, edulcorante Esteviosídeo da marca STEVITA, ácido cítrico e conservante fosfato de cálcio. Para o processamento da geléia extra foram utilizadas as uvas das variedades Rubi e Benitaka, açúcar cristal comum, ácido cítrico e pectina cítrica GENU ${ }^{\circledast}$ tipo 105. Para a elaboração do suco foram utilizadas uvas da variedade Benitaka.

\subsection{Obtenção dos extratos enzimáticos da POD e da PPO das uvas}

As uvas foram selecionadas, lavadas em água destilada e degranadas. A seguir foram homogeneizadas com $50 \mathrm{~mL}$ de solução tampão fosfato de sódio $100 \mathrm{mM}$, em $\mathrm{pH}$ 6,0, por 2 minutos, utilizando um liqüidificador. Durante o processo, foram acrescentados polivinilpirrolidona (PVPP) $1 \% \mathrm{p} \cdot \mathrm{v}^{-1}$ para inibição de compostos fenólicos e traços de $\mathrm{CaCl}_{2}$ para inibição da ação da pectina. A solução foi filtrada com tecido de algodão e recolhida em béquer, em banho de gelo. O filtrado foi centrifugado a $17000 \mathrm{~g}$ por 20 minutos e temperatura de $0{ }^{\circ} \mathrm{C}$. O sobrenadante denominado fração enzimática solúvel foi congelado $-18^{\circ} \mathrm{C}$.

O precipitado foi homogeneizado com $100 \mathrm{~mL}$ de $\mathrm{NaCl} 1 \mathrm{M}$, em solução tampão fosfato de sódio $100 \mathrm{mM}$, em pH 6,0. A solução foi centrifugada nas mesmas condições citadas anteriormente. O sobrenadante denominado extrato enzimático ionicamente ligado foi também estocado a $-18{ }^{\circ} \mathrm{C}$.

\subsection{Determinação da atividade da POD das uvas}

A atividade da POD foi determinada seguindo o método descrito por Clemente (1998). Em 0,2 mL do extrato enzimático adicionou-se $2,7 \mathrm{~mL}$ de peróxido de hidrogênio $0,1 \%$, o qual foi preparado em solução tampão fosfato de sódio $(100 \mathrm{mM}$ e pH 6,0) e em seguida foi adicionado $0,1 \mathrm{~mL}$ de solução de o-dianisidina $1 \%$ em metanol. A leitura foi realizada em espectrofotômetro e usando $460 \mathrm{~nm}$. Uma unidade de atividade de peroxidase foi definida como o correspondente à variação de uma unidade de absorbância por minuto/mL de amostra.

\subsection{Determinação da atividade da PPO das uvas}

A atividade da PPO foi determinada de acordo com o método descrito por LIMA (ROBINSON, 1987), com modificações. Após a mistura de $0,5 \mathrm{~mL}$ do extrato enzimático com $0,8 \mathrm{~mL}$ de solução tampão fosfato de sódio ( $100 \mathrm{mM} \mathrm{e} \mathrm{pH} \mathrm{6,0),} \mathrm{e} \mathrm{finalmente}$ 0,05 mL de solução de catecol 0,01 M, a solução resultante foi incubada a $30{ }^{\circ} \mathrm{C}$ por 30 minutos. Em seguida, acrescentou-se 0,8 $\mathrm{mL}$ de ácido perclórico $2 \mathrm{M}$. A leitura foi realizada em espectrofotômetro a $395 \mathrm{~nm}$. Uma unidade de atividade de PPO foi definida como o correspondente à variação de uma unidade de absorbância por minuto/mL de amostra.

\subsection{Determinação das atividades residuais dos extratos enzimáticos após tratamento térmico}

Os extratos enzimáticos das variedades Rubi e Benitaka obtidos conforme item 2.1 foram submetidos a tratamentos térmicos com temperaturas de $60,70,80$ e $85^{\circ} \mathrm{C}$, por períodos de $0,1,2,3,4,6,8$ e 10 minutos. As atividades residuais das enzimas POD e PPO foram determinadas como descrito, respectivamente, em 2.2 e 2.3 .

\subsection{Elaboração de sucos e geléias extra e light utilizando uvas fora do padrão de comercialização}

As uvas das variedades Rubi e Benitaka fora do padrão para consumo foram utilizadas para a elaboração de geléias light e extra (Fluxogramas das Figuras 1 e 2), as quais foram produzidas em escala piloto em março de 2006.

Na elaboração do suco foram utilizadas as uvas da variedade Benitaka, como descrito no Fluxograma da Figura 3.

\subsection{Obtenção dos extratos enzimáticos da POD e da PPO de sucos}

Volumes de $50 \mathrm{~mL}$ de suco foram homogeneizados com 50 mL de solução tampão (fosfato de sódio 100 mM e pH 6,0) por 2 minutos, utilizando um liqüidificador. Para a determinação das atividades enzimáticas seguiram-se os procedimentos descritos anteriormente, nos itens 2.2 e 2.3 . 


\subsection{Obtenção dos extratos enzimáticos da POD e da PPO das geléias light e extra}

Quantidades de $50 \mathrm{~g}$ de geléias light e extra foram homogeneizadas, separadamente, com $50 \mathrm{~mL}$ de solução tampão por 2 minutos, utilizando um liqüidificador. Para a determinação das atividades enzimáticas seguiram-se os procedimentos descritos anteriormente, nos itens 2.2 e 2.3 .

\subsection{Análise microbiológica}

Determinou-se o Número Mais Provável de coliformes totais e termotolerantes (NMP.g ${ }^{-1}$ ) além da contagem de bolores e leveduras (UFC. ${ }^{-1}$ ) para as geléias light e extra. Essas análises foram realizadas seguindo procedimentos descritos por Vanderzant e Splittstoesser (1992).

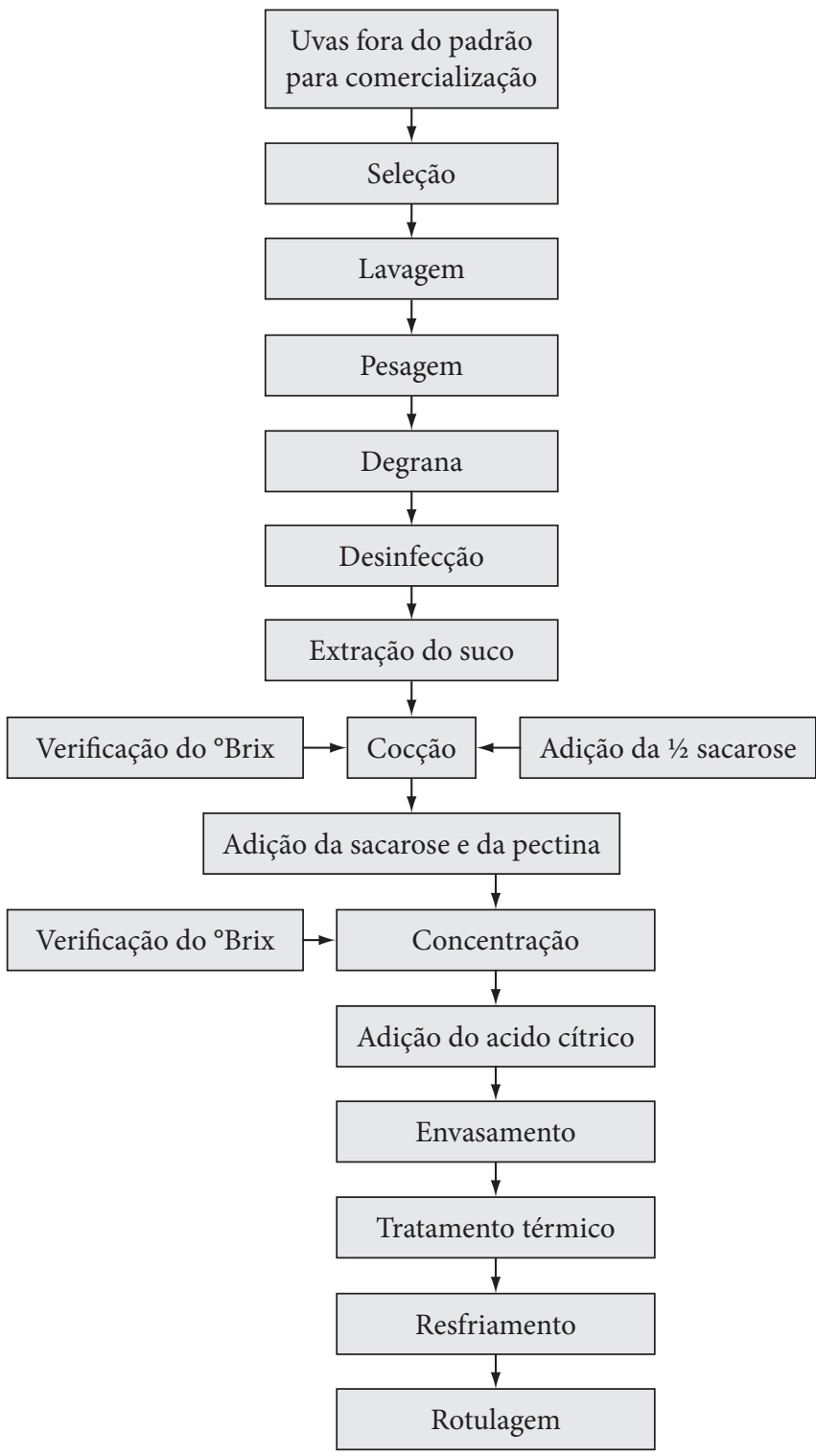

Figura 1. Fluxograma para obtenção da geléia extra de uva.

\subsection{Análise estatística}

Os resultados foram tratados estatisticamente através da Análise de Variância (ANOVA) e da aplicação do teste de Tukey entre as médias, a 5\% de probabilidade, por meio do programa estatístico Statistical Analysis Sistem (SAS, 1999).

\section{Resultados e discussão}

A atividade da peroxidase foi semelhante nos extratos das duas variedades Benitaka e Rubi (Tabela 1), tanto para a fração solúvel quanto para a fração ligada. Já a atividade da polifenoloxidase foi muito superior na variedade Rubi, cerca de setenta vezes maior que na Benitaka. Tropiani, Tropiani e Clemente (2003), em experimentos nos quais avaliaram a pele da varie-

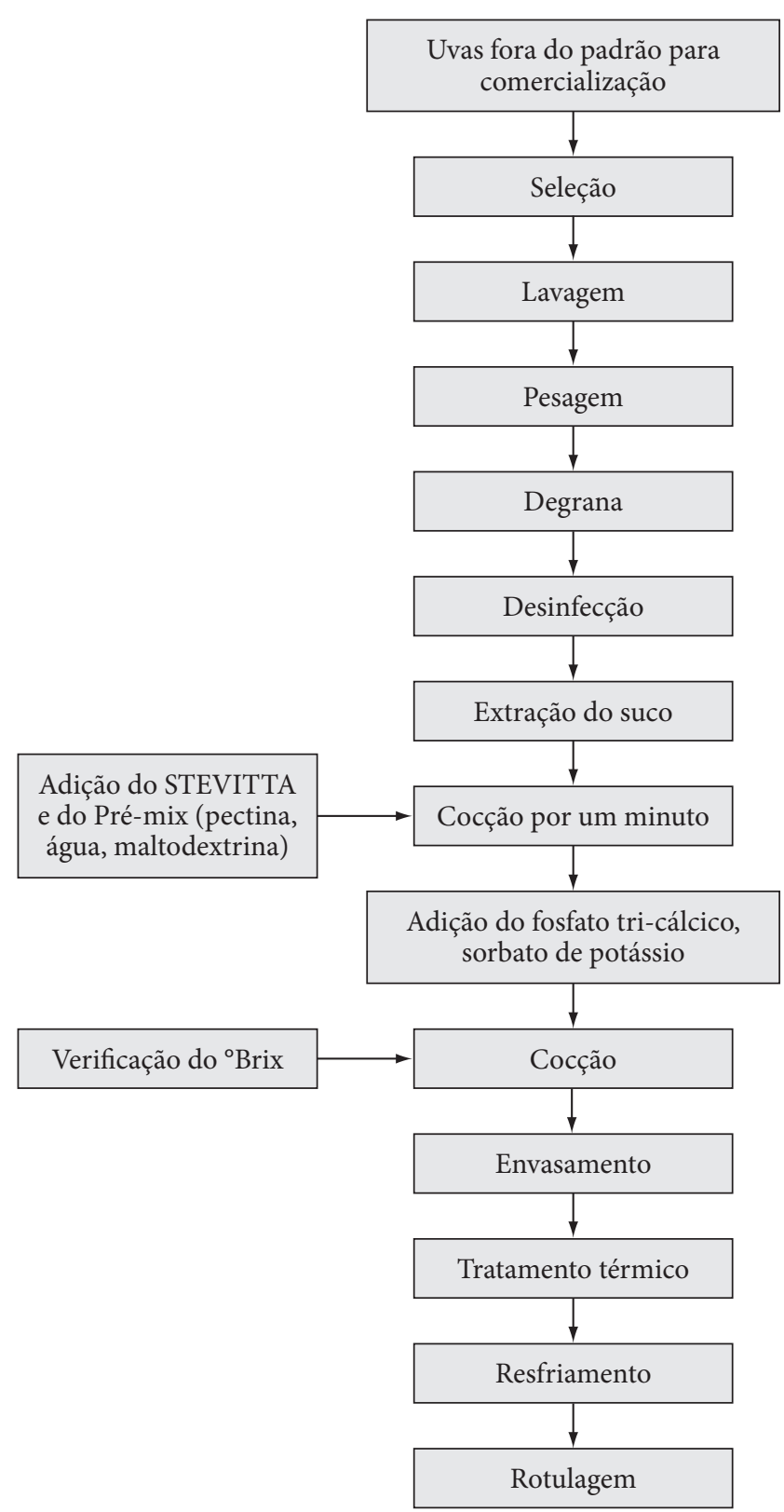

Figura 2. Fluxograma para obtenção da geléia light de uva. 


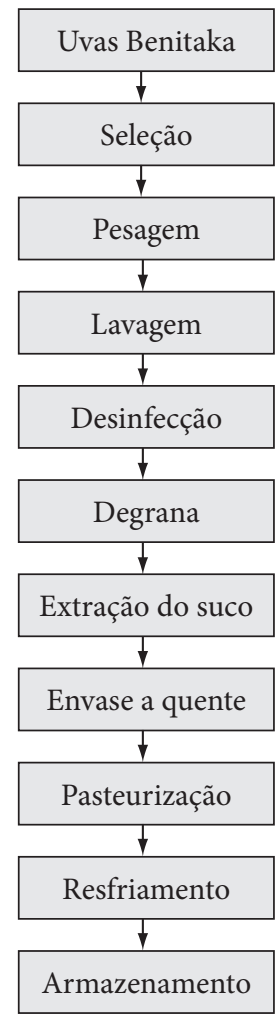

Figura 3. Fluxograma para obtenção do suco de uva.

Tabela 1. Atividade enzimática da PPO E POD das variedades de uvas frescas fora do padrão para comercialização das variedades Benitaka e Rubi.

\begin{tabular}{lcc}
\hline & Benitaka & Rubi \\
\hline Peroxidase (unid/min/mL) & 2,63 & 2,65 \\
Peroxidase ligada (unid/min/mL) & 2,97 & 2,83 \\
Polifenoloxidase (unid/min/mL) & 0,014 & 0,97 \\
\hline
\end{tabular}

dade Benitaka, encontraram para a atividade da peroxidase um valor ligeiramente superior ao encontrado na pesquisa atual. No entanto, determinaram valores inferiores para a peroxidase e a polifenoloxidase na polpa das variedades Rubi e Benitaka.

Alterações no conteúdo das enzimas PPO e POD podem ocorrer durante o armazenamento, podendo estar associadas à senescência dos tecidos das bagas, o que envolve aumento da atividade da peroxidase, prejudicando a qualidade das uvas (CENCI, 1994).

As Figuras 4, 5, 6 e 7 apresentaram, respectivamente, o comportamento da termoestabilidade da PPO na variedade Benitaka, PPO na variedade Rubi, POD na variedade Benitaka e POD na variedade Rubi. O tratamento térmico para a peroxidase e para a polifenoloxidase mostrou ser um processo não linear, o que está em concordância com Valderrama, Marangoni e Clemente (2001), que observaram esse tipo de comportamento em seus estudos com essas enzimas em maçãs. Verificou-se no caso destas variedades de uva um decréscimo quase contínuo.

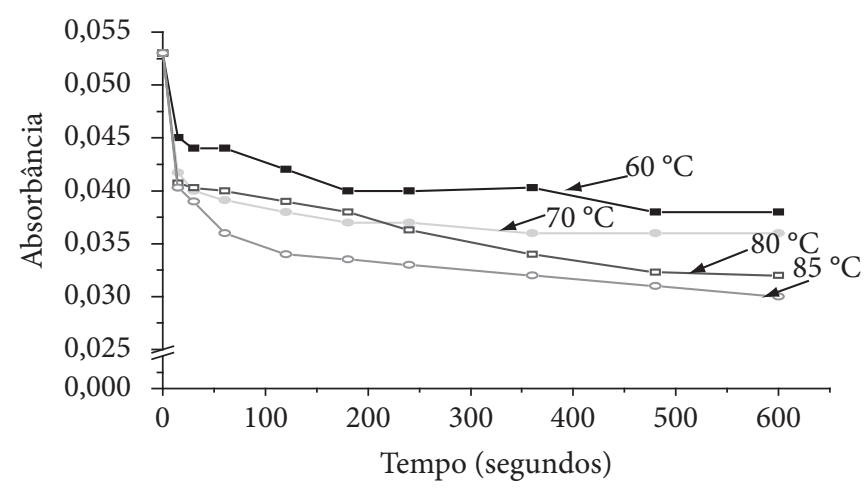

Figura 4. Atividade residual da PPO na uva da variedade Benitaka.

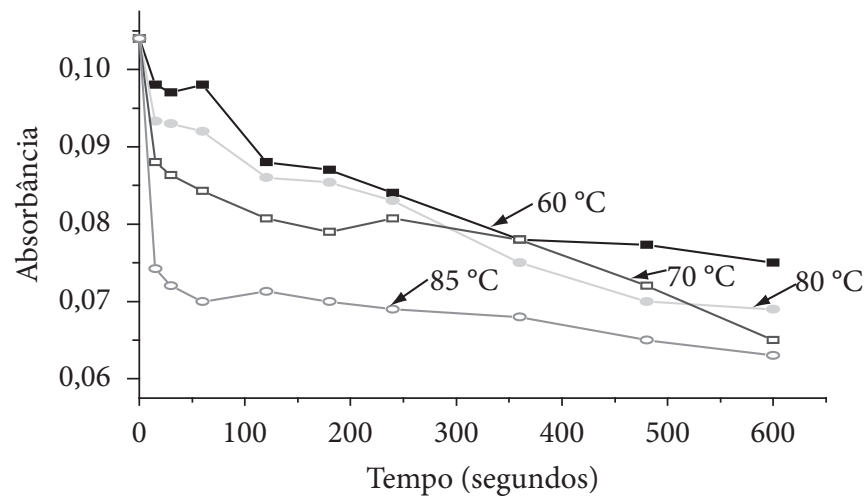

Figura 5. Atividade residual da PPO na uva variedade Rubi.

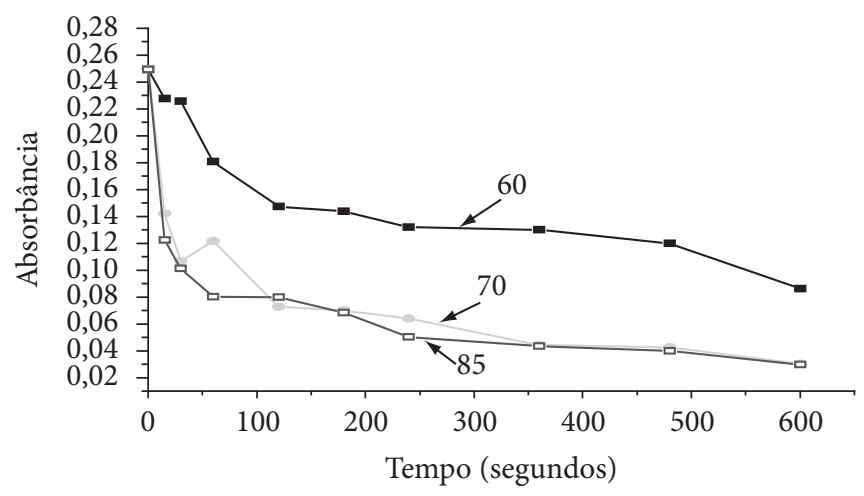

Figura 6. Atividade residual da POD na uva da variedade Benitaka.

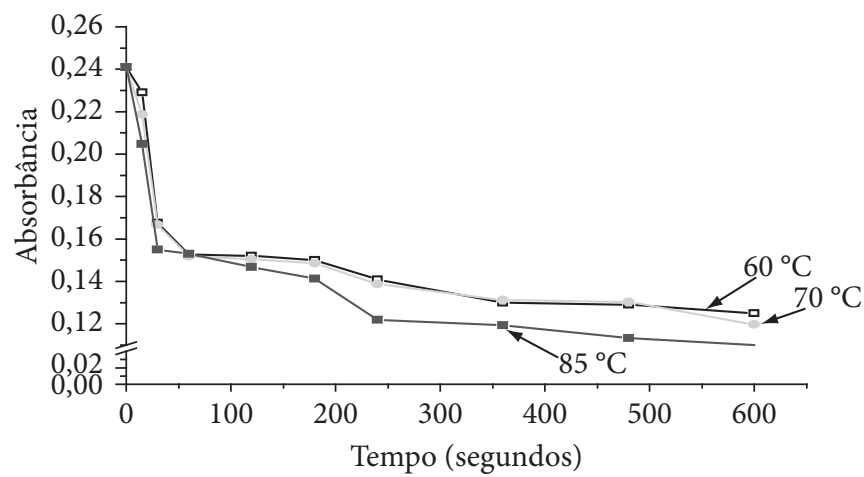

Figura 7. Atividade residual da POD na uva da variedade Rubi. 
As atividades da POD e PPO nos extratos enzimáticos das uvas das variedades Benitaka e Rubi diminuíram com o tempo de exposição do extrato enzimático à temperatura de tratamento e também com o aumento da temperatura. Assim, uma maior inativação enzimática foi obtida na temperatura de $85^{\circ} \mathrm{C}$ e com tempo de exposição de 10 minutos (Figura 6), no entanto, observou-se que os tratamentos térmicos utilizados não foram suficientes para a total inativação das enzimas.

As temperaturas utilizadas para a concentração das geléias, bem como para a extração e pasteurização do suco, causaram diminuição da atividade enzimática da $\mathrm{PPO}$ e POD, porém, não foram suficientes para a total inativação das enzimas. Como se observa na Tabela 2 , os produtos processados ainda apresentaram uma atividade enzimática residual; esses valores diferem estatisticamente entre si; assim o suco de uva apresentou maior atividade enzimática, seguido da geléia extra e geléia light.

Segundo Furtunato (2002), as enzimas podem se tornar novamente ativas após a inativação térmica, fenômeno conhecido por renaturação, o qual ocorre com algumas enzimas depois de cessado o agente causador da desnaturação, no caso o tratamento térmico. É fato conhecido que essa tendência é maior quando o resfriamento que segue o tratamento térmico é lento.

As geléias e sucos se apresentaram de acordo com os padrões estabelecidos pela legislação vigente (BRASIL, 2001) quanto aos coliformes, bolores e leveduras (Tabela 3), indicando que os processamentos ocorreram em condições higiênicosanitárias satisfatórias e com tratamentos térmicos eficientes. Os resultados das análises microbiológicas de geléias light estão de acordo com dados obtidos por Granada et al. (2005), nos quais a incidência e o crescimento de microrganismos do grupo coliforme e de bolores e leveduras foram inferiores a 3 NMP.g ${ }^{-1}$ e de 30 UFC. ${ }^{-1}$, respectivamente.

\section{Conclusões}

As atividades da enzima POD, tanto da fração solúvel quanto da ionicamente ligada, foram semelhantes nas uvas das variedades Benitaka e Rubi.

A atividade da enzima polifenoloxidase foi maior na variedade Rubi. Uma maior inativação enzimática foi obtida na temperatura de $85^{\circ} \mathrm{C}$ e tempo de exposição de 10 minutos.

Tabela 2. Determinações das atividades enzimáticas residuais da PPO e POD de produtos processados de uva.

\begin{tabular}{lccc}
\hline & $\begin{array}{c}\text { Geléia } \\
\text { light }\end{array}$ & $\begin{array}{c}\text { Geléia } \\
\text { extra }\end{array}$ & Suco \\
\hline Peroxidase (unid/min/mL) & $0,07^{\mathrm{c}}$ & $0,22^{\mathrm{b}}$ & $0,51^{\mathrm{a}}$ \\
Polifenoloxidase (unid/min/mL) & $0,06^{\mathrm{c}}$ & $0,43^{\mathrm{b}}$ & $1,51^{\mathrm{a}}$ \\
\hline
\end{tabular}

Tabela 3. Características microbiológicas das geléias light, extra e do suco.

\begin{tabular}{lccl}
\hline & $\begin{array}{c}\text { Geléia } \\
\text { light }\end{array}$ & $\begin{array}{c}\text { Geléia } \\
\text { extra }\end{array}$ & Suco \\
\hline Coliformes totais NMP.g $^{-1}$ & $<3$ & $<3$ & $<3$ \\
Coliformes termotolerantes NMP.g $^{-1}$ & $<3$ & $<3$ & $<3$ \\
Bolores e leveduras UFC.g $^{-1}$ & $<10^{4}$ & $<10^{4}$ & $<10^{4}$ \\
\hline
\end{tabular}

Os processos utilizados para a elaboração das geléias e sucos foram eficientes para garantir a qualidade microbiológica, de acordo com a legislação.

\section{Agradecimentos}

À CAPES pela bolsa de mestrado, à FUNDAÇÃO ARAUCÁRIA pelo apoio financeiro do projeto, à Cooperativa dos Fruticultores de Marialva pelo fornecimento das uvas e à STEVIA FARMA INDUSTRIAL pelo fornecimento dos edulcorantes.

\section{Referências bibliográficas}

BARTHOLO, G. F. Perdas e qualidade preocupam. Informe Agropecuário, Belo Horizonte, v. 17, n. 179, p. 4, 1994.

BRASIL. Ministério da saúde, Secretaria de Vigilância Sanitária. Resolução RDC n 12, 02 jan. 2001. Regulamento técnico sobre padrões microbiológicos para alimentos. Diário Oficial da República Federativa do Brasil, Brasília, n. 7-E, 10 jan. 2001. p. 45-53.

CENCI, S. A. Acido naftalenoacético (ANA) e cloreto de cálcio na précolheita de uva niágara rosada (Vitis labrusca $\mathrm{L}$. $\mathrm{X}$ Vitis vinifera L.): Avaliação do potencial de conservação no armazenamento. Lavras, 1994, 109 p. Tese (Doutorado em Ciências dos Alimentos) - Escola Superior de Agricultura de Lavras.

CLEMENTE, E. Purification and termostability of isoperoxidase from oranges. Phytochemistry, Kidlington/Oxon, v. 49, p. 29-36, 1998.

CLEMENTE, E.; PASTORE, G. M. Peroxidase and polyphenoloxidase, the importance for food technology. Ciênc. Tecnol. Aliment., Campinas, v. 32, n. 2 p. 167- 171, 1998.

FURTUNATO, A. A. Estudo da cinética de inativação térmica da pectina esterase e peroxidase presente na polpa de cajá (Spondias lútea). Rio Grande do Norte, 74p. 2002. Dissertação (Mestre em Engenharia Química) - Faculdade de Engenharia Química, Universidade Federal do Rio Grande do Norte (UFRN).

GIOVANNINI, E. Produção de uvas para vinho, suco e mesa. 2. ed. Porto Alegre: RENASCENÇA, 1999.

GRANADA, G. G. et al. Caracterização física, química, microbiológica e sensorial de geléias light de abacaxi. Cienc. Tecnol. Aliment., Campinas, v. 25, n. 4, p. 629-635, 2005.

LEE, C. Y.; PENNESI, A. P.; DICKSON, M. H. Characterization of cauliflower peroxidase isoenzyme. J. Agr. And Food Chem., Washington, v. 32, n. 1, p. 18-21, 1984.

LIMA, E. D. P.; PASTORE, G. M.; LIMA, C. A. A. Purificação da enzima polifenoloxidase (PPO) de polpa de pinha (Annona squamosa L.). Cienc. Tecnol. Aliment., Campinas, v. 21, n. 1, p. 98-104, 2001.

ROBINSON, D. S. Food Biochemistry and Nutritional Value. Logman Scientific and Technical: Essex, 1987. 320 p.

ROSENTHAL, A.; RODRIGUES, A. M.; SLONGO, A. P. Cinética de Inativação Térmica da Peroxidase de Suco de Manga. In: XVII CONGRESSO BRASILEIRO DE FRUTICULTURA, Pelotas - RS, 2003, Anais..., Pelotas - RS: Sociedade Brasileira de Fruticultura, 2003.

SAS - Statistical Analisys Sistem. Sas Institute Inc., Cary, NC, USA, 1999.

SATO, G. S. et al. Canais de distribuição na cadeia produtiva da uva fina no estado de São Paulo. In: REUNIÃO ANUAL DO INSTITUTO BIOLÓGICO, 17º RAIB, 2004, Resumos... São Paulo - SP: Instituto Biológico, 2004, v. 71. p. 117- 131. 
SCIANCALEPORE, V.; ALVITI, F. S. Preliminary study on multipleform of peroxidase from Malavasia grapes. Lebesmittel - Wissenschaft and Technologie, Zurich, v. 18, n. 2, p. 174-177, 1985.

SORIANO, A.; CLEMENTE, E. Minerais e enzimas oxidativas em brócolos (Brassica oleracea L. Cv. Italica) minimamente processado. Acta Scientiarum, Maringá, v. 24, n. 6, p. 1615-1618, 2002.

TROPIANI, E. P.; TROPIANI, C. T.; CLEMENTE, E. Peroxidase (POD) and polyphenoloxidase (PPO) in grape (Vitis vinifera L.). Ciênc. Agrotec., Lavras. v. 7, n. 3, p. 635-642, 2003.
VALDERRAMA. P.; MARANGONI, F.; CLEMENTE, E. Efeito do tratamento térmico sobre a atividade de peroxidase (POD) e polifenoloxidase (PPO) em maçã (Mallus comunis) Ciênc. Tecnol. Aliment., Campinas, v. 2, n. 3, p. 321-325, 2001.

VANDERZANT, C.; SPLITTSTOESSER, D. F. Compedium for the Microbiological Examination of Foods. 3. ed. Washington: Public Health Association, 1992, 1219 p. 